Anales de Geografía de la Universidad Complutense ISSN: 0211-9803

\title{
Incisión fluvial del río Darro durante el periodo 1890-2010 en el sector urbano de Granada (Alhambra-Valparaíso, España) determinada a partir de fotografías históricas
}

\author{
José Manuel García-Aguilar ${ }^{1}$; Antonio Guerra-Merchán²; Francisco Javier Suárez Medina ${ }^{3}$ \\ Recibido: 17 de marzo del 2016 / Enviado a evaluar: 22 de mayo del 2016 / Aceptado: 18 de julio del 2016
}

Resumen. En este trabajo se calcula la tasa media de incisión fluvial del río Darro (Granada, España) durante el periodo 1890-2010 en su tramo urbano (sector Alhambra-Valparaíso). Para ello se han utilizado fotografías históricas en las que aparece dicho río, a partir de las cuales se ha podido determinar la posición del cauce en el momento en el que se realizaron las fotografias. La comparación con los escenarios actuales de tales imágenes ha permitido determinar la diferencia de altura del cauce a través de medidas de cotas absolutas realizadas mediante teodolito. Esta metodología ha permitido estimar de modo cuantitativo un índice de encajamiento vertical medio del río de $1,05 \mathrm{~cm} /$ año para el periodo histórico considerado.

Palabras clave: Incisión fluvial; río Darro; Granada; fotografías.

[en] Vertical erosion of the Darro river during the period 1890-2010 (Alhambra-Valparaíso, Granada, Spain) evaluated by historical pictures

\footnotetext{
Abstract. In this paper, the average rate of the river Darro incision (Granada, Spain) is calculated over the historical period 1890-2010 in the urban section (Alhambra-Valparaiso sector). This has been used historical photographs that this river appears, from which it has been possible to determine the position of the channel at the time when the photographs were made. Comparison with the current scenarios has identified the height difference of the channel through absolute coordinates measures undertaken by theodolite. This methodology has allowed quantitatively estimate an index of mean vertical engagement of the river for the data collection time of $1,05 \mathrm{~cm} /$ year.

Keywords: fluvial incision; Darro river; Granada; photographs.

1 Departamento de Ecología y Geología. Facultad de Ciencias. Universidad de Málaga.

E-mail: jmg.aguilar@gmail.com

2 Departamento de Ecología y Geología. Facultad de Ciencias. Universidad de Málaga.

E-mail: antguerra@uma.es

3 Departamento de Mecánica de Estructuras e Ingeniería Hidráulica. E.T.S. de Ingenieríos de Caminos, Canales y Puertos. Universidad de Granada.

E-mail: fjsuarez@ugr.es
} 
[fr] Rivière Darro incision de la rivière pendant la période 1890-2010 dans certaines zones urbaines de Grenade (Alhambra-Valparaiso, Espagne) à partir de photographies historiques

Résumé. Dans cet article, le taux moyen de fluviatile rivière Darro incision (Grenade, Espagne) est calculée sur le période 1890-2010 dans sa section urbaine (Alhambra - Valparaiso secteur). Cela a été utilisé des photographies historiques dans lesquelles cette rivière apparaît, à partir de laquelle il a été possible de déterminer la position de la piste au moment où les photos ont été prises. Comparaison avec les scénarios actuels de ces images a permis de déterminer la différence de hauteur du canal grâce à des mesures prises par les dimensions absolues théodolite. Cette méthodologie a permis d'estimer quantitativement un taux montage vertical moyen de la rivière $1,05 \mathrm{~cm} /$ an pour la période considéré.

Mots clés: Incision fluviatile; lrivière Darro; Grenade; photographies.

Cómo citar. García-Aguilar, J.M.; Guerra-Merchán, A. y Suárez Medina, F.J. (2016): Incisión fluvial del río Darro durante el periodo 1890-2010 en el sector urbano de Granada (alambra-Valparaíso, España) determinada a partir de fotografías históricas. Anales de Geografía de la Universidad Complutense, 36(2), 307-320.

Sumario. 1. Introducción. 2. Contexto geográfico y geológico. 3. Metodología y cuantificación de la incisión fluvial. 4. Discusión. 5. Conclusiones. 6. Bibliografía.

\section{Introducción}

Los procesos geológicos superficiales resultan normalmente difíciles de cuantificar. Las velocidades de esos procesos son calculadas a menudo mediante la siguiente fórmula matemática (Gardner et al., 1987): $\mathrm{S}=\Delta \mathrm{x} / \Delta \mathrm{t}=(\mathrm{X} 2-\mathrm{X} 1) /(\mathrm{T} 2-\mathrm{T} 1)$. Para el caso del cálculo de la incisión fluvial, X1 sería la altura del cauce actual y T1 corresponde a la actualidad (tiempo 0 años), mientras que X2 representa la altura de un elemento sedimentario y/o geomorfológico anterior y $\mathrm{T} 2$ la edad del mismo.

Para la estimación de tasas de incisión fluvial se han utilizado una cierta variedad de formas de relieve y/o depósitos asociados a la evolución de los valles fluviales, para los cuales se cuenta con dataciones precisas. Las formas de relieve más utilizadas para este fin son las terrazas fluviales (Amorosi et al., 1996; Burbank et al., 1996; González et al., 1996; Schaller et al., 2002, 2004; Cunha et al., 2008; Schulte et al., 2008; Ruiz Fernández; Poblete Piedrabuena, 2011; Romero Díaz et al., 2011, entre otros). Otros elementos de la superficie que han permitido estos cálculos son: espeleotemas (Smart, 1986), depósitos de travertinos (Ortiz et al., 2010), superficies morfoestructurales (Peres Rokhas et al., 2006; Antón y Muñoz Martín, 2007), coladas de lava recientes en las divisorias de aguas o que rellenan los valles (Menéndez-González et al., 2004), superficies de abanicos aluviales (Arboleya et al., 2008), superficies de glacis y sedimentos vulcano-clásticos (Bès de Berc et al., 2004), terrazas de ablación (Bès de Berc, 2003) y superficies rocosas cuya exposición ha sido datada a partir de la concentración de nucleidos cosmogénicos (Schaller et al., 2005).

Existe un antecedente donde se han estimado tasas de erosión fluvial lineal mediante el empleo de fotografías históricas (Conesa García y Pérez Cutillas, 2014), demostrando 
así la validez de este método en ausencia de datos más precisos. Por tanto, en casos donde no se dispone de rasgos geomorfológicos datados con precisión, puede ser considerada esta herramienta de cara a controlar la altura del cauce a lo largo del tiempo. En este sentido, el río Darro, a su paso por el entorno urbano de Granada, ha sido y sigue siendo en la actualidad un importante elemento de referencia sociocultural, ya que su curso bajo atraviesa la zona donde se encuentran la Alhambra, el Generalife y el barrio de Sacromonte. El interés mostrado por fotógrafos por recoger escenas de estos enclaves a lo largo de los siglos, ha permitido que actualmente se disponga de una amplia base documental de fotografías elaboradas desde el siglo XIX, donde aparece posicionado el río Darro (Colina Munguía, 1980; Gallego y Burín, 1982; Serrera Contreras, 1990; Bustos Rodríguez, 1998 y 2003; Girón López, 2000; Caja Granada y Fundación Emasagra, 2009). El interés geológico de estas fotografías radica en poder reconocer y determinar en ellas la posición del cauce del río Darro en el pasado. De esta forma, comparándola con la posición actual, se puede aplicar una metodología que permita cuantificar la tasa de incisión del río desde el momento en el que se realizaron las fotografías hasta la actualidad.

\section{Contexto geográfico y geológico}

El río Darro, con un recorrido total de $22 \mathrm{~km}$, forma parte de la red fluvial existente en el entorno de la ciudad de Granada, la cual tiene su origen en los relieves situados al Este, Nordeste y Sureste de la misma, correspondientes a los macizos montañosos de Sierra Nevada y Sierra de Huétor (Figura 1). El nacimiento del río Darro se halla en el Parque Natural de la Sierra de Huétor a una cota de 1.450 m, constituyéndose su caudal inicial mediante infiltración y escorrentías en zonas de alta precipitación relativa (unos $1.000 \mathrm{~mm} / \mathrm{año}$ ). Su cuenca hidrográfica presenta un carácter pluvial, una extensión cercana a $81 \mathrm{~km}^{2}$ y un caudal anual medio en su zona de desembocadura de unos $5 \mathrm{hm}^{3} /$ año.

Desde su nacimiento, el cauce transcurre en dos tramos principales de dirección característica (Figura 1). El primero, de orientación N190E y una longitud de 14 km, marca la cuenca alta del río. El segundo tramo, de unos $7 \mathrm{~km}$, comienza en la zona de Jesús del Valle, a cota $850 \mathrm{~m}$, donde el curso del río gira bruscamente unos $100^{\circ}$ hacia el Oeste hacia una orientación N290E, marcando el inicio de su cuenca baja. Ya en el entorno urbano de Granada, y con una longitud próxima a un kilómetro, el cauce vuelve a girar en dirección Sur hasta su desembocadura en el río Genil, a unos $670 \mathrm{~m}$ de altura, alcanzando en este punto una diferencia de cota de unos $800 \mathrm{~m}$ desde su nacimiento. Otros valores fisiográficos de interés se refieren a la anchura de su cauce, con un máximo de 10 a 15 m, y la creación de un marcado perfil en "V" en su valle, especialmente en su tramo bajo (zona Sacromonte-Alhambra, denominada aquí como "Valparaíso"), donde muestra una profundidad máxima de $230 \mathrm{~m}$. En este tramo se observa también que las laderas tienen diferente pendiente, siendo la ladera sur más inclinada, con unos $40^{\circ}$, mientras que la ladera norte muestra una pendiente media de $22^{\circ}$ (Figura 1). 
Figura 1. Contexto geográfico del río Darro (imagen superior)
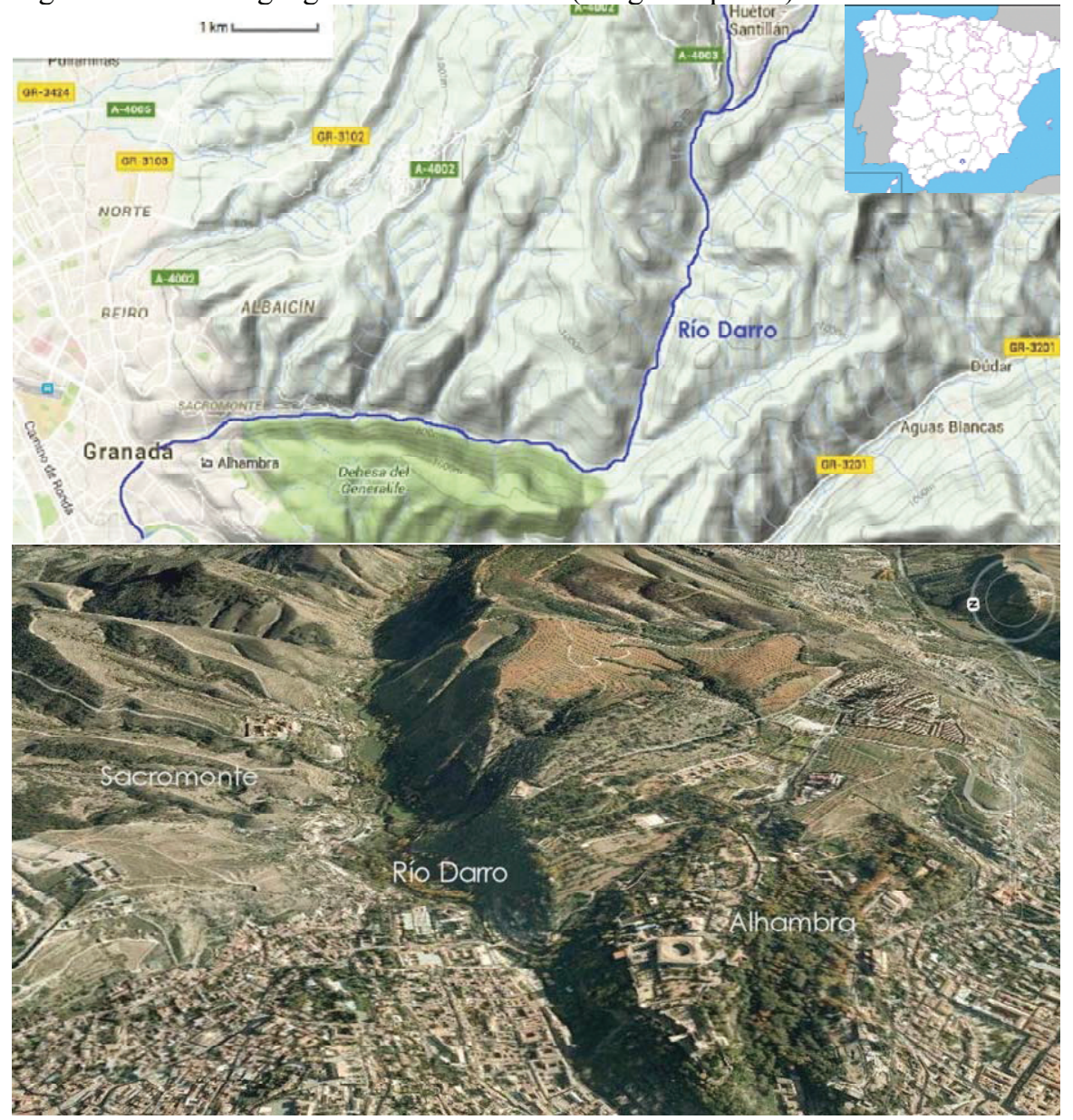

Fuente: Elaboración propia, a partir de Goolge Earth y Google Maps ${ }^{4}$.

Una vez que el río Darro supera la Sierra de Huétor, se adentra en uno de los grandes dominios geológicos que forman Andalucía (Figura 2), la depresión neógena de Granada. Esta depresión constituye una cuenca intramontañosa rellenada por depósitos sedimentarios post-orogénicos de edad Mioceno superior-Cuaternario (últimos 12 millones de años), divididos en dos grandes conjuntos litoestratigráficos

4 Fuente de la imagen superior: Google Earth, modificada. Fuente de la imagen inferior: Google Maps, modificada, e imagen aérea virtual del valle del río Darro en el sector Alhambra-Sacromonte 
separados por una discordancia: materiales miocenos de afinidad marina (conglomerados, arenas, calcarenitas, limos, margas y evaporitas) y materiales pliocuaternarios (conglomerados, arenas, lutitas y yesos) de origen continental (Lupiani Moreno y Soria Mingorance, 1988; Rodríguez-Fernández et al., 1989; Braga et al., 1990; Martín, 2000; García-Alix et al., 2008). El tramo bajo del río Darro transcurre por conglomerados de edad Plioceno que pertenecen a la Formación Alhambra. Estos conglomerados, con una potencia máxima de $250 \mathrm{~m}$ (Figura 3), caracterizan el depósito de abanicos aluviales coalescentes que se formaron al pie de los relieves de las sierras que limitaban por el Este la cuenca de Granada. La etapa sedimentaria final de los abanicos aluviales de la Formación Alhambra culmina con la formación de un glacis que se sitúa a una cota media de $1.000 \mathrm{~m}$ y muestra una pendiente topográfica media de $0,016 \%$ al Este del recinto de la Alhambra.

Figura 2. Localización del sector de Granada en el contexto geológico de la Cordillera Bética (izquierda) y mapa geológico general del sector del río Darro (derecha).

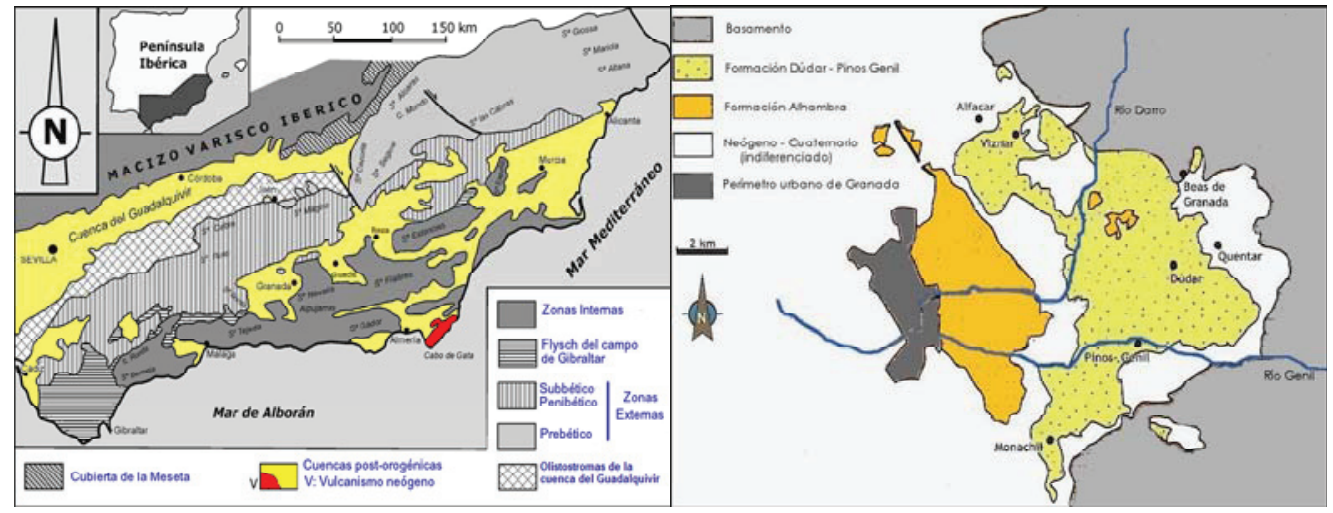

Fuente: Mapa de la izquierda elaboración propia y mapa de la derecha modificado de Martín (2000).

\section{Metodología y cuantificación de la incisión fluvial}

Para este estudio se han seleccionado tres fotografias antiguas con suficiente nitidez y contraste donde aparece el río Darro en el tramo urbano considerado, junto a elementos arquitectónicos o urbanos que se pueden reconocer en la actualidad y, por tanto, servir de referencia. A partir de estas fotografías se ha reconocido la posición que tenía el cauce en ese momento y con la ayuda de tales elementos arquitectónicos (puentes, murallas, edificios, etc.) que se reconocen en la fotografía y están presentes actualmente, se ha marcado la antigua posición del cauce sobre el escenario actual. Esto permite medir la diferencia de cota entre la posición actual del cauce y la posición que ocupaba en el pasado en cada fotografía. Conociendo el año en el que se realizó cada una de las fotografías, se puede calcular la tasa promedio de incisión del cauce. Las mediciones de 
tales diferencias de cota se han llevado a cabo con total precisión mediante alturas absolutas con un teodolito Leica modelo TCRP-1203 con posicionamiento automático mediante sistema láser y GPS integrado.

Figura 3. Imágenes del valle del río Darro en su tramo bajo ${ }^{5}$.
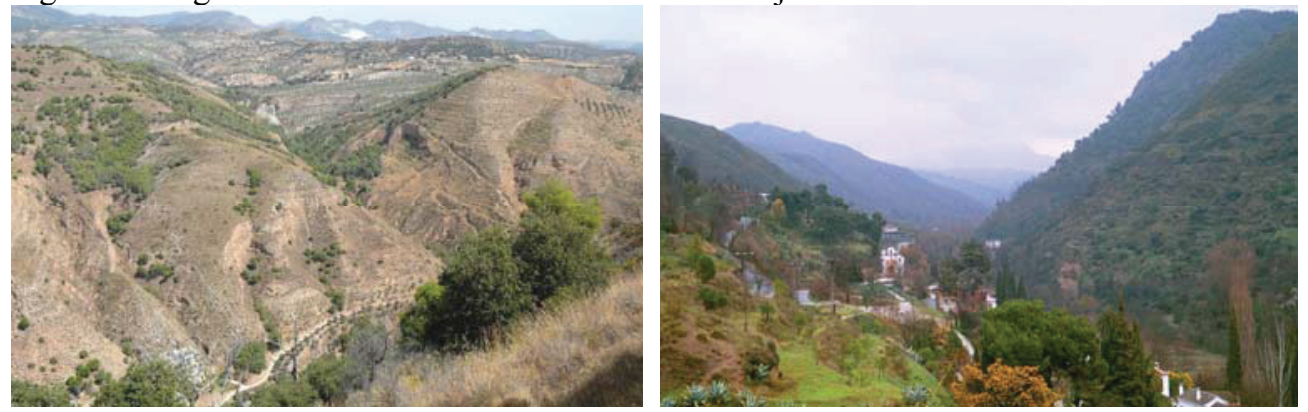

Fuente: Elaboración propia.

La primera fotografía considerada es del año 1890 y fue tomada en el entorno de la Iglesia de San Pedro, situada junto al cauce del río Darro (Figura 4A). Esta fotografía tiene una fácil comparación con la misma escena tomada en el año 2010 (Figura 4B). Llevadas a cabo las medidas pertinentes, se comprueba como la cota relativa del río en 2010 ha descendido 136,6 cm respecto a su posición en 1890, tomando como referencia la altura del muro inferior de la iglesia $(743 \mathrm{~cm})$ situado en la vertical de la torre del campanario, según muestra la imagen de 2010 (Figura 4B). A partir de estos datos, se estima una tasa de incisión vertical en el río Darro de 1,14 cm/año. Además, se aprecia una reducción en la anchura del cauce actual y un mayor nivel de encajamiento frente a la que presentaba a finales del siglo XIX.

La segunda fotografía es del año 1900 y muestra el cauce del río Darro en la vertical de la Torre de Comares, perteneciente al conjunto arquitectónico de la Alhambra (Figura 5A). La imagen permite estimar la cota de referencia del río en ese momento mediante su calibración respecto a la altura del muro exterior y una imagen similar tomada en 2010 (Figura 5B). La comparación entre ambas imágenes y las medidas de campo efectuadas revelan que el trazado del cauce en 1900 se hallaba a $137,3 \mathrm{~cm}$ sobre el nivel actual del río. Estos valores numéricos permiten calcular una tasa de incisión de 1,25 cm/año.

Imágenes del valle del río Darro en su tramo bajo, mostrando el aspecto de los conglomerados de la Formación Alhambra en primer plano (izquierda, fecha de la imagen: mayo de 2009), en el sector Alhambra-Sacromonte (derecha, fecha de la imagen: febrero de 2008). 
Figura 4. Comparación entre las imágenes obtenidas del río Darro junto a la iglesia de San Pedro, en 1890 (A) y 2010 (B) ${ }^{6}$.
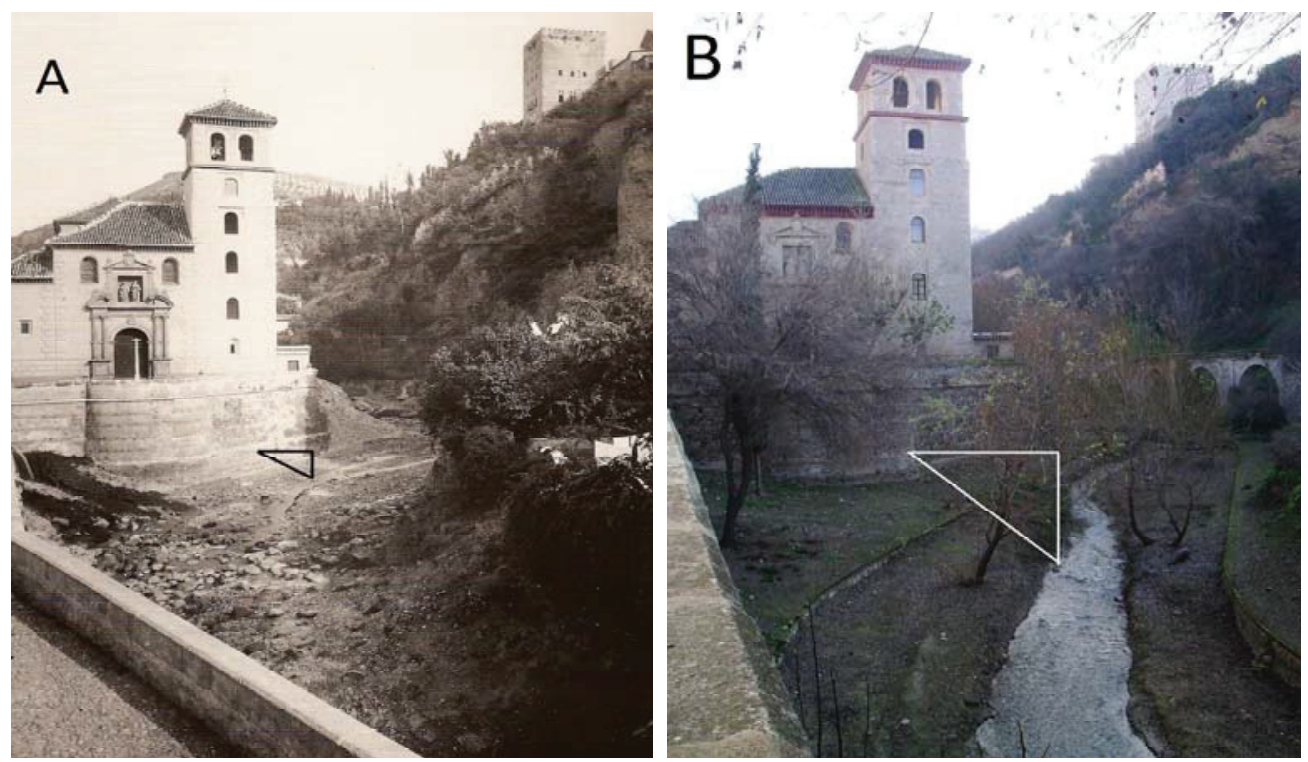

Fuente fotografía A: Bustos Rodríguez (1998); fotografía B: Elaboración propia.

La tercera fotografía considerada es del año 1910, correspondiente al tramo urbano del río (Figura 6A), permite su comparación con una imagen similar obtenida en 2010 (Figura 6B). En este caso se ha medido la altura del puente de Espinosa en el lado derecho de la imagen hasta la marca donde transcurre el cauce del río en la imagen de $1910(608 \mathrm{~cm})$ y la altura del cauce en 2010 respecto a la misma referencia $(683,9$ $\mathrm{cm})$. Estos valores permiten deducir un descenso de 75,9 cm en la cota del río a lo largo de 100 años, lo que se traduce en una tasa media de encajamiento vertical de $0,76 \mathrm{~cm} / a n ̃ o$. En estas imágenes, además, se aprecia como el cauce del río ha reducido su anchura desde casi 4 metros hasta poco más de 1,5 metros, además de mostrar un pequeño nivel de aterrazamiento a la izquierda de la imagen de 2010, originada con toda probabilidad mediante procesos de encajamiento reciente en el cauce.

6 Comparación entre las imágenes obtenidas del río Darro en 1890 (A) y noviembre de 2010 (B), junto a la iglesia de San Pedro, mediante la triangulación marcada en las imágenes. 
Figura 5. Comparación entre las imágenes obtenidas del río Darro bajo la Torre de Comares (recinto Alambra), en 1900 (A) y 2010 (B)
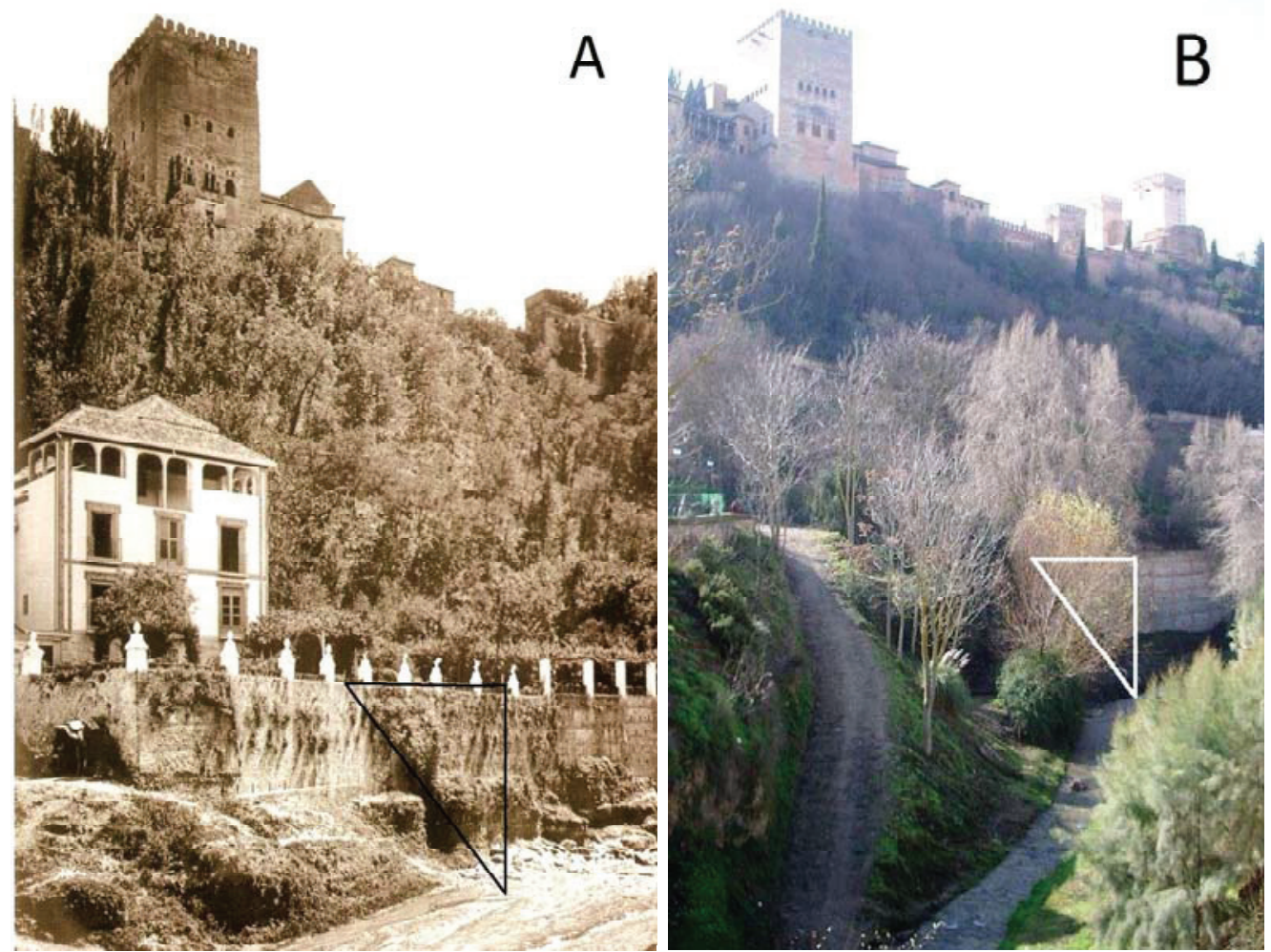

Fuente fotografía A: Caja Granada y Fundación EMASAGRA (2009); fotografía B: Elaboración propia.

\section{Discusión}

La validez del método empleado cabe someterla a una serie de consideraciones. Un primer elemento de validez respecto a los datos obtenidos consiste en detectar posibles actuaciones urbanísticas significativas en el tramo considerado del río Darro que hayan inducido cambios en su trazado, en la cota del cauce o en los elementos

7 Fotograma del año 1900 (A) que representa el cauce del río Darro bajo la Torre de Comares (recinto de la Alhambra), y el mismo escenario en una imagen de enero de 2010 (B). En ambas imágenes se ha marcado la triangulación empleada para los cálculos de incisión fluvial. 
arquitectónicos usados como referencia. La información obtenida al respecto en los archivos municipales del Ayuntamiento de Granada, Confederación Hidrográfica del Guadalquivir y la empresa abastecedora de aguas de Granada (EMASAGRA), revelan que dichas actuaciones no han supuesto en el último siglo cambios que afecten sustancialmente a la dinámica natural de río, al no llevarse a cabo labores tales como dragados, represas, desviaciones o trasvases. Así mismo, no se recogen actuaciones que hayan modificado de modo sustancial la estructura de los puentes y muros tomados como referencia. En este sentido, las labores de acondicionamiento y amurallado en el sector de la Iglesia de San Pedro y el Paseo de los Tristes durante la segunda mitad del siglo XX no se consideran relevantes como factores de modificación en sus tasas de encajamiento vertical. Por otra parte, no se han documentado en la zona, durante el periodo de tiempo considerado, deslizamientos de ladera significativos, roturaciones o actuaciones agrícolas que hayan modificado las condiciones naturales de la zona.

Figura 6. Comparación entre las imágenes obtenidas del río Darro en el entorno del Puente de Espinosa (centro histórico), en 1910 (A) y 2010 (B) ${ }^{8}$.
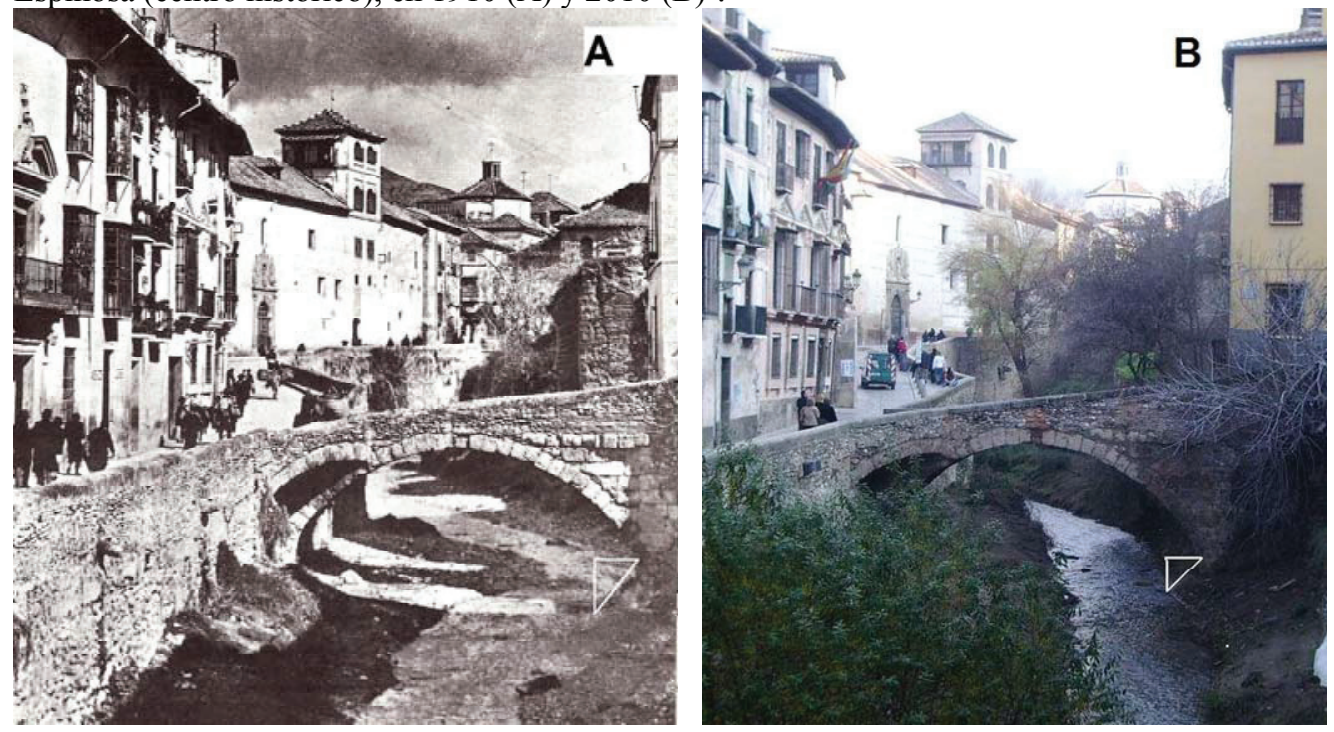

Fuente fotografía A: http://vuelvoagranada.blogspot.com/ (año 2012); fotografía B: Elaboración propia.

8 Comparación entre las imágenes obtenidas del río Darro en 1910 (A) y abril de 2010 (B) en el entorno del Puente de Espinosa (centro histórico de Granada), mediante la triangulación marcada en las imágenes. 
Por otro lado, los valores obtenidos sobre las tasas de incisión vertical del cauce cabe someterlos a crítica respecto a los momentos donde fueron obtenidas las imágenes consideradas para el estudio, y que pudieran corresponder a situaciones excepcionales de crecida en el caudal o bien de nivel anormalmente bajo. En relación a este factor, observaciones empíricas llevadas a cabo a lo largo del periodo 20002010 demuestran que el caudal del río Darro expone unas variaciones estacionales limitadas, si exceptuamos los meses de verano donde el caudal el río es menor o aquellos periodos de crecidas históricas o excepcionales, no recogidas en los testimonios gráficos considerados.

De este modo, los 13 periodos de crecidas catastróficas registradas en los años 1478, 1600 (que dio lugar al Tajo de San Pedro, bajo la Alhambra, debido a un colosal desprendimiento), 1614, 1629 (cuya crecida llegó a inundar la Catedral de Granada y causó más de 100 víctimas mortales), 1803, 1835, 1839, 1851, 1860, 1887 (que provocó el colapso del recién acabado embovedado del Darro en el centro de la ciudad), 1949, 1951 y 1963 (Ayala-Carcedo et al., 1986; Girón López, 2000; Azañón et al., 2007), se consideran causantes en mayor medida de la excavación vertical en el cauce y la formación de los pequeños niveles de paleoterrazas observados. Por consiguiente, los datos planteados deben entenderse como valores promedio, aunque ilustrativos acerca de la dinámica erosiva de este río en el sector y plazo temporal considerados.

La Tabla I muestra de forma sintética los datos y resultados obtenidos a partir del análisis de las fotografías históricas. Estos datos permiten calcular una tasa media de incisión en el cauce del río Darro, en el tramo considerado, de $1,05 \mathrm{~cm} / \mathrm{año}$ para el periodo 1890-2010.

Tabla 1. Síntesis de resultados obtenidos.

\begin{tabular}{|c|c|c|c|c|}
\hline $\begin{array}{c}\text { Fecha de la } \\
\text { imagen }\end{array}$ & $\begin{array}{c}\text { Diferencia } \\
\text { temporal } \\
\text { considerada }\end{array}$ & $\begin{array}{c}\text { Diferencia de } \\
\text { cota en el cauce }\end{array}$ & $\begin{array}{c}\text { Tasa de incisión } \\
\text { media (cm/año) }\end{array}$ & Comentarios \\
\hline 1910 & 100 años & $75,9 \mathrm{~cm}$ & 0,76 & $\begin{array}{c}\text { La anchura del río era } \\
\text { de } 4 \text { m, más del doble } \\
\text { que la actual }\end{array}$ \\
\hline 1900 & 110 años & $137,3 \mathrm{~cm}$ & 1,25 & $\begin{array}{c}\text { Cauce desplazado } \\
\text { unos } 8 \text { macia el Sur }\end{array}$ \\
\hline 1890 & 120 años & $136,6 \mathrm{~cm}$ & 1,14 & $\begin{array}{c}\text { Anchura del río muy } \\
\text { superior a la actual. } \\
\text { Menor encajamiento }\end{array}$ \\
\hline
\end{tabular}

Fuente: Elaboración propia.

Este valor medio en la incisión vertical en el tramo bajo del río Darro de 1,05 cm/año, en el periodo 1890-2010, cabe compararlo con otros datos de referencia existentes en la bibliografía. Es este sentido, Azañón et al., (2007) citan valores de 
encajamiento de la red fluvial de Granada (en este caso en referencia al río Genil, cauce donde desemboca el río Darro) entre 0,02 y $0,04 \mathrm{~cm} /$ año teniendo en cuenta para ello la profundidad del valle y una edad en el inicio del encajamiento fluvial en el borde Este de la depresión de Granada estimada en el Pleistoceno medio (en torno a 0,5 millones de años), correspondiente a la edad de los últimos depósitos sedimentarios situados en los abanicos aluviales de La Zubia (Martín y Braga, 1997).

De este modo, vemos como el valor histórico de $1,05 \mathrm{~cm} /$ año resulta entre 26 y 53 veces superior al calculado para el conjunto de su historia erosiva de la red fluvial presente en el borde Este de la depresión de Granada. La interpretación de este hecho induce a considerar una tendencia no lineal para este proceso ligada a mecanismos de aceleración en las tasas de incisión del río en épocas recientes, posiblemente debidas a un descenso en su nivel de base o bien debidas a un ascenso tectónico relativo del terreno (Strahler, 1979; MOPT, 1992; Pedraza, 1996). Además, resulta lógico considerar tasas de incisión fluvial mucho más bajas, en torno a 0,5-1 mm/año, si consideramos periodos de tiempo del orden de decenas o cientos de miles de años (González et al., 1996; Menéndez González et al., 2004), puesto que en estos casos suceden etapas de sedimentación y etapas de equilibrio entre erosión y sedimentación en los lechos fluviales, lo que reduce considerablemente la tasa media de incisión calculada.

\section{Conclusiones}

A través del análisis de fotografías históricas obtenidas del río Darro (Granada) correspondientes al periodo 1890-2010, susceptibles de ser comparadas objetivamente con los mismos escenarios actuales que exponen, se ha estimado una tasa media de encajamiento en el tramo urbano del río de 1,05 cm/año. Si consideramos el conjunto de su historia erosiva, cifrada en unos 0,5 millones de años atrás, la tasa de incisión descendería a valores situados entre 0,02 y $0,04 \mathrm{~cm} / \mathrm{año}$, lo que indica una tendencia no lineal para este factor.

Se destaca la validez del método utilizado como herramienta para determinar de modo objetivo y cuantitativo este proceso geomorfológico para épocas históricas, presentando, así mismo, un elevado potencial de cara a la evaluación de otros procesos geomorfológicos tales como cambios en las redes de drenaje, datación de eventos fluviales (riadas, desprendimientos, etc.) o actuaciones antrópicas sobre el paisaje.

\section{Bibliografía}

Amorosi, A., Farina, M., Severi, P., Preti, D., Caporale, L. y Di Dio, G. (1996): Genetically related alluvial deposits across active fault zones: an example of alluvial fan-terrace correlation from the upper Quaternary of the southern Po Basin, Italy. Sedimentary Geology, 102, 275-295. 
AntónN, L. y Muñoz Martín, A. (2007): Controles tectónicos y estructurales de la incisión fluvial en el centro-oeste de la Cuenca del Duero, NO Iberia. Geogaceta, 43, 51-54.

Arboleya, M.L., Babault, J., Owen, L.A., Teixell, A. y Finkel, R.C. (2008): Timing and nature of Quaternary fluvial incision in the Ouarzazate foreland basin, Morocco. Journal of the Geological Society, London, 165, 1059-1073.

Ayala-Carcedo, F.J., Rodríguez-OrtiZ, J.M., Prieto Alcolea, C., Durán Valsero, J.J., Lamas Romero, J.L. y Rubio Amo, J. (1986): Mapa previsor de riesgos por inundaciones en núcleos urbanos de Andalucía y Extremadura. Instituto Geológico y Minero de España (Madrid).

Azañón, J.M., Azor, A., De Justo Alpañés, J.L., Martín Rosales, W., Mateos, R. y Pérez-Peña, V. (2007): Deslizamientos e inundaciones cuaternarias en la cuenca vertiente del río Darro: la génesis del Tajo de San Pedro (La Alhambra, Granada). Resúmenes XII reunión Nacional del Cuaternario, 13-14.

Bès De Berc, S. (2003): Tectonique de Chevauchement, Surrection et incisión fluviatile (Exemple de la Zone Subandine Equatorienne, Haut Bassin Amazonien). PhD thesis, Toulouse III, Paul Sabatier, 181 páginas.

Bès De Berc, S., Baby, P., Soula, J., Rosero, J., Souris, M., Christophoul, F. y Vega, J. (2004): La superficie Mera-Upano: Marcador Geomorfológico de la incisión fluviatil y del levantamiento tectónico de la Zona Subandina Ecuatoriana. En Baby, P., Rivadeneira, M. y Barragán, R. (Editores): La Cuenca Oriente: Geología y Petróleo, Travaux de l'Institut Français d'Études Andines, 144, 153-167.

Braga, J.C., Martín, J.M. y Alcalá, B. (1990): Coral reefs in coarse-terrigeous sedimentary environments (Upper Tortonian, Granada Basin, Southern Spain). Sedimentary Geology, $66,135-150$.

Burbank, D.W., Leland, J., Fielding, E., Anderson, R.S., BrozoviC, N., et al. (1996): Bedrock incision, rock uplift and threshold hillslopes in the northwestern Himalayas. Nature, 379, 505-510.

Bustos Rodríguez, J. (1998): Granada siempre viva. Homenaje a José García Ayola (18851890). Diario Ideal (Granada) - Caja General de Ahorros de Granada.

Bustos RodrígueZ, J. (2003): Granada: un caudal de emociones. Diario Ideal (Granada).

Caja Granada - Fundación EMASAGRA. (2009): Dauro, un río en la imagen de la ciudad. Obra cultural de la Caja de Ahorros de Granada (Granada).

Colina Munguía, S. (1980): Los ríos de Granada. Obra cultural de la Caja de Ahorros de Granada (Granada).

Cunha, P. P., Martins, A. A., Huot, S., Murray, A. y Raposo, R. (2008): Dating the Tejo river lower terraces in the Ródão area (Portugal) to asses the role of tectonics and uplift. Geomorphology, 102, 43-54.

Conesa García, C. y Pérez Cutillas, P. (2014): Alteraciones geomorfológicas recientes en los sistemas fluviales mediterráneos de la Península Ibérica. Síntomas y problemas de incisión en los cauces. Revista de Geografía Norte Grande, 59.

Gallego y Burín, A. (1982): Guía artística e histórica de la ciudad. Sevilla, Editorial Don Quijote (Granada). 
García-Alix, A., Minwer-Barakat, R., Martín, J.M., Martín Suárez, E. y Freudenthal, M. (2008): Biostratigraphy and sedimentary evolution of late Miocene and Pliocene continental deposits of the Granada Basin (Southern Spain). Lethaia, 41, 431-446.

Gardner, T. W., Jorgensen, D. W., Shuman, C. y Lemieux, C. R. (1987): Geomorphic and tectonic process rates: Effects of measured time interval. Geology, 15, 259-261.

Girón López, C. (2000): En torno al Darro, El valle del Oro. Colección Granada y sus barrios. Caja General de Ahorros de Granada - Obra social (Granada).

González, A., Díaz, J. R., Barba, F. J., Remondo, J. y Cendrero, A. (1996): Propuesta de un modelo cronológico para las terrazas de los ríos de la vertiente cantábrica. Geogaceta, 20 (5), 1096-1099.

Lupiani Moreno, E. y Soria Mingorance, J. (1988): Mapa geológico de España escala 1:50.000 segunda serie (MAGNA). Hoja de Granada (1009). Instituto Geológico y Minero de España (IGME). Servicio de Publicaciones del Ministerio de Industria, Madrid.

Martín, J.M. (2000): Geología e historia del oro en Granada. Boletín Geológico y Minero, 111 (2 y 3 ), 47-60.

Martín, J.M. y Braga, J.C. (1997): Sierra Nevada. Historia del levantamiento de un relieve deducida de las unidades conglomeráticas de su borde. En Calvo, J.P. y Morales, J. (Eds.): Avances en el conocimiento del Terciario ibérico. Universidad Complutense de MadridMuseo Natural de Ciencias Naturales, 117-120.

Menéndez González, I., Martín Betancur, M. y Silva, P.G. (2004): Morfología de perfiles longitudinales, tasas de incisión y elevación en el sector Norte de la isla de Gran Canaria (España). Revista Cuaternario y Geomorfología, 18 (3-4), 15-27.

Ministerio de Obras Públicas y Transportes (MOPT). (1992): Guía para la elaboración de estudios del medio físico. Madrid.

Ortiz menéndez, J. E., Torres Pérez-Hidalgo, T., Llamas Borrajo, J., Díaz Bautista, M. y Moreno Pérez, L. (2010): Cálculo de tasas de incisión a partir de travertinos fluviales. Aplicación a la gestión de residuos radiactivos. Publicación tecnológica y docente de la Escuela de Minas de Madrid, 7, 174-183.

Pedraza, J. (1996): Geomorfología: principios, métodos y aplicaciones. Editorial Rueda (Madrid).

Peres Pokhas, A. y García-Hidalgo, J.F. (2006): Morfología, procesos erosivos y evolución reciente en una cárcava cuaternaria: El barranco Haza de la Viña, Uceda (Guadalajara, España). Boletín de la Real Sociedad Española de Historia Natural. Sección de Geología, 101, 1-4.

Rodríguez-Fernández, J., Sanz de Galdeano, C. y Fernández, J. (1989): Genesis and evolution of the Granada Basin (Betic Cordillera, Spain). En Thauasuthipitak, T.P. y Ounchnum, P. (Eds.): Intermontane basins: Geology and resources. Chiang_Mai, Thailand, 294-305.

Romero Díaz, M.A., Ruiz Sinoga, J.D, Belmonte Serrato, F. (2011): Tasas de erosión hídrica en la región de Murcia. Boletín de la Asociación de Geógrafos Españoles, 56, 129-153.

Ruiz Fernández, J. y Poblete Piedrabuena, M.A. (2011): Las terrazas fluviales del río Cares: aportaciones sedimentológicas y cronológicas (Picos de Europa, Asturias). Estudios Geográficos, 72 ( $\left.\mathrm{n}^{\circ} 270\right), 173-202$. 
Schaller, M., Von Blanckenburg, F., Veldkamp, A., Tebbens, L.A., Hovius, N. y Kubik, P.W. (2002): A $30000 \mathrm{yr}$ record of erosion rates from cosmogenic ${ }^{10} \mathrm{Be}$ in Middle European river terraces. Earth and Planetary Science Letters, 204, 307-320.

Schaller, M., Von Blanckenburg, F., Hovius, N., Veldkamp, A., Meindert, W., Van Den Berg, W. y Kubik, P.W. (2004): Paleoerosion rates from cosmogenic ${ }^{10} \mathrm{Be}$ in a $1.3 \mathrm{Ma}$ terrace sequence: response of the River Meuse to changes in climate and Rock uplift. The Journal of Geology, 112, 127-144.

Schaller, M., Hovius, N., Willett, S. D., Ivy-Ochs, S., Synal, H.-A. y Chen, M.-C. (2005): Fluvial bedrock incision in the active mountain belt of Taiwan from in situ-produced cosmogenic nuclides. Earth Surface Processes and Landforms, 30, 955-971.

Schulte, L., Julià, R., Burjachs, F. y Hilgers, A. (2008): Middle Pleistocene to Holocene geochronology of the River Aguas terrace sequence (Iberian Peninsula): Fluvial response to Mediterranean environmental change. Geomorphology, 98, 13-33.

Serrera Contreras, R.M. (1990): El Darro y la Granada romántica. Caja General de Ahorros de Granada (Granada).

Smart, P.L. (1986): Origin and development of glacio-karst closed depressions in the Picos de Europa, Spain. Zeitschrift für Geomorphologie N. F., 30, 423-443.

Strahler, A. (1979): Geografía física. Editorial Omega. Barcelona.

\section{Agradecimientos}

Agradecemos la generosidad que nos ha brindado la Dirección General de Administración Local de la Región de Murcia, y también la Dirección General de Política Local del Gobierno de La Rioja, pues gracias a su vocación de servicio público ha sido posible tener acceso toda una serie de datos esenciales para este trabajo. Del mismo modo, es nuestro deseo expresar el reconocimiento a labor científica prestada por los revisores que han sometido a análisis este artículo, destacando su profesionalidad y rigurosidad; en ese sentido, deseamos mostrar nuestro agradecimiento sincero por la ayuda recibida, así como por las interesantes sugerencias facilitadas hasta alcanzar la versión definitiva de este documento. Sin lugar a dudas, constituyen la clave de bóveda para el desarrollo de una revista científica. 